\title{
Decomposition and Decoupling Analysis of Energy-Related Carbon Emissions from China Manufacturing
}

\author{
Qingchun Liu, Shufang Liu, and Lingqun Kong \\ School of Economics, Shandong University of Finance and Economics, Jinan 250014, China \\ Correspondence should be addressed to Qingchun Liu; lqc7919@163.com
}

Received 25 July 2015; Accepted 3 September 2015

Academic Editor: Xinguang Zhang

Copyright (C) 2015 Qingchun Liu et al. This is an open access article distributed under the Creative Commons Attribution License, which permits unrestricted use, distribution, and reproduction in any medium, provided the original work is properly cited.

\begin{abstract}
The energy-related carbon emissions of China's manufacturing increased rapidly, from $36988.97 \times 10^{4}$ tC in 1996 to $74923.45 \times$ $10^{4} \mathrm{tC}$ in 2012. To explore the factors to the change of the energy-related carbon emissions from manufacturing sector and the decoupling relationship between energy-related carbon emissions and economic growth, the empirical research was carried out based on the LMDI method and Tapio decoupling model. We found that the production scale contributed the most to the increase of the total carbon emissions, while the energy intensity was the most inhibiting factor. And the effects of the intrastructure and fuel mix on the change of carbon emissions were relatively weak. At a disaggregative level within manufacturing sector, EI subsector had a greater impact on the change of the total carbon emissions, with much more potentiality of energy conservation and emission reduction. Weak decoupling of manufacturing sector carbon emissions from GDP could be observed in the manufacturing sector and EI subsector, while strong decoupling state appeared in NEI subsector. Several advices were put forward, such as adjusting the fuel structure and optimizing the intrastructure and continuing to improve the energy intensity to realize the manufacturing sustainable development in low carbon pattern.
\end{abstract}

\section{Introduction}

Carbon emissions amount from China has already surpassed the United States since 2007 and has been the number one in the world [1]. Increasing trend of carbon emissions from China has received the great attention with the global warming. Both energy saving and emission reduction are becoming more and more important for Chinese government, who was committed to reducing carbon dioxide emissions per unit of GDP by $40-45 \%$ in 2020 to be less than 2005 levels on the Copenhagen Climate Change Conference in 2009. Manufacturing sector's, as the core of China economy, product value surpassed the United States for the first time in 2011 and became the number one in the world. But the development of China manufacturing sector has been depending on the high energy consumption for a long time, and it was responsible for approximately $82.54 \%$ of China's final energy demand in 1995-2006 [2]. Therefore, how to realize the manufacturing sustainable development in low carbon pattern is the biggest challenge for China in future. However, China's manufacturing sector has great energy saving potentiality and space due to excessive dependence on resources and energy consumption [3]. Thus, it is necessary to study the changes of energy-related carbon emissions over time and to explore the main driving factors to increase carbon emissions from China manufacturing sector, as well as the relationship between carbon emissions and economic growth in order to help meet the government target.

\section{Literature Review}

2.1. Decomposition Carbon Emissions. Decomposition analysis can divide the changes in carbon emissions over time into a number of different factors, which help us better understand the reasons for the changes observed. The broad technique of decomposition analysis undertaken here is often known as IDA, due to the advantage of its simplicity, the availability of statistical data, and the ease of historical comparison. There are a number of different methods available within IDA, and the Log Mean Divisia Index method I (LMDI I) is perfect in decomposition, having no residual term, which 
is used here in decomposition carbon emissions due to the adaptability and ease of use $[4,5]$. Using LMDI I method, many studies were carried out on carbon emissions from China in the last decade. Dong and Zhang [6] applied LMDI to decompose the energy-related carbon emissions from China industry into the production scale, carbon emissions intensity, energy structure, and energy intensity, and the findings showed that industrial production scale plays direct role in increasing carbon emissions. Wei and Xia [7] studied per-capita carbon emissions from the world and found that reducing the energy intensity and developing renewable clear energy were the only two major ways to realize low carbon economy under the background of increasing income and high energy dependence on coal. Song [8] also studied energy-related carbon emissions of Shandong Province in China and decomposed the carbon emissions into population, average wealth, intrastructure, and energy intensity, and pointed out that only the energy intensity had the negative effect on carbon emissions. Hammond and Norman [9] used the LMDI method to make decomposition analysis of energy-related carbon emissions from UK manufacturing sector and separated the contributions of changes in output, intrastructure, energy intensity, fuel mix, and electricity emission factor to the reduction in carbon emissions.

\subsection{Decoupling Analysis between Carbon Emissions and Eco-} nomic Growth. Many studies show the carbon emissions are strongly connected to the economic growth [10-13], and the target of low carbon economy is to sustain the decoupling state between the carbon emissions and economic growth. The concept of decoupling is first proposed by Organization for Economic Cooperation and Development (OECD), who divided it into absolute decoupling and relative decoupling [14]. Tapio [15] further expanded the decoupling theory, distinguished eight logical possibilities of decoupling, and studied the decoupling situations relationships between GDP, traffic volumes, and $\mathrm{CO}_{2}$ emissions from transport in the EU15 countries in 1970-2001; Zhuang [16] applied Tapio model and studied the decoupling relationship between $\mathrm{CO}_{2}$ emission and economic growth in Taiwan. Wang et al. [1] explored the decoupling relationship between energy-related carbon emissions and economic growth in Guangdong and found that its decoupling state turns from weak decoupling in 1996 to strong decoupling state in 2011. Li et al. [17] employed Tapio decoupling index to analyze the relationship between rural and urban construction land. Compared with OECD decoupling index, Tapio decoupling model has been widely used in empirical verification owing to the advantage of ease of adaptability, ease of use, and ease of understanding.

In summary, previous studies mainly focused on the carbon emissions from industry or the total carbon emissions amount in a certain nation or region, while few of them focused on the carbon emissions from manufacturing sector and the relationship between energy-related carbon emissions and economic growth in China [18]. Moreover, the changes of carbon emissions at disaggregative level lack analysis, but it is necessary for government to consider the differences of subsectors when making energy saving policies and measures. Therefore, the paper studies the changes of energy-related carbon emissions from China manufacturing over the years from 1996 to 2012, decomposes it in production scale, intrastructure, energy intensity and fuel mix, and carbon emissions coefficient by the means of LMDI, makes the decoupling analysis between energyrelated carbon emissions and economic growth, and decomposes the total decoupling elasticity into energy conservation, carbon emissions reduction, output value, and industrial development. In addition, the manufacturing sector is split into two subsectors, energy-intensive (EI) subsector and nonenergy-intensive (NEI) subsector; the carbon emissions of each subsector is decomposed, as well as the decoupling analysis.

\section{Methods and Data Resource}

3.1. Defining Energy-Intensive and Energy-Intensive Subsector. The manufacturing sector here is defined by Standard Industrial Classification (SIC) codes 1-30 according to China Statistical Yearbook, excluding the artwork and other subsectors (SIC code 29) and recycling subsector (SIC code 30) omitted for the limited data. The details of remaining 28 subsectors are shown in Table 1. Manufacturing sectors can be divided into EI and NEI subsectors, based on the extent of energy dependence and the potential strength of drivers to energy intensity improvement [9], and there are three criteria including the aggregate energy intensity of a subsector, the proportion of total financial costs represented by energy and water for a subsector, and the mean energy use per enterprise in a subsector. Given the limited data, the paper chooses the aggregate energy intensity value of $64.6 \mathrm{TJ} / 10^{8}$ Yuan as the division criteria [9]. And five subsectors whose values are over the threshold are classified as the EI sector; they are manufacture of pulp, paper, and paper products (SCI code 10), manufacture of petroleum processing, coking, and nuclear fuel (SCI code 13), manufacture of chemicals and chemical products (SCI code 14), manufacture of other nonmetallic mineral products (SCI code 19), and manufacture of ferrous metal smelting and rolling (SCI code 20), and the remaining 23 subsectors are classified as the NEI sectors; all of them are labeled in Table 1. The average energy intensity in the EI subsector is $365.25 \mathrm{TJ} / 10^{8}$ Yuan, which is 9.19 times of that in the NEI subsector.

3.2. Calculation of Energy-Related Carbon Emissions from Manufacturing Sector. Energy consumption includes the end-use energy consumption by manufacturing sector and energy consumption by production of thermal power and heat power. The paper just calculated the end-use energy consumption for the limited data. There are 16 types of energy mainly consumed in the manufacturing sector, including coal, crude oil, natural gas, and other fossil fuels from Energy Balance Sheet of China Energy Statistical Yearbook. Carbon emissions coefficient of each fuel could be calculated referenced by 2006 IPCC Guidelines for National Greenhouse Gas Inventories [19]. Based on these, the carbon emissions of 28 manufacturing subsectors could be calculated, as well as the total manufacturing sector. 
TABLE 1: Subsector split of the manufacturing sector.

\begin{tabular}{|c|c|c|}
\hline SCI code & Manufacturing subsector & EI/NEI \\
\hline 1 & $\begin{array}{l}\text { Manufacture of agricultural and } \\
\text { sideline products }\end{array}$ & NEI \\
\hline 2 & Manufacture of food products & NEI \\
\hline 3 & Manufacture of beverages & NEI \\
\hline 4 & Manufacture of tobacco products & NEI \\
\hline 5 & Manufacture of textiles & NEI \\
\hline 6 & $\begin{array}{c}\text { Manufacture of garment, shoes, and } \\
\text { hat }\end{array}$ & NEI \\
\hline 7 & Manufacture of leather, fur, and feather & NEI \\
\hline 8 & $\begin{array}{l}\text { Manufacture of wood and wood } \\
\text { products }\end{array}$ & NEI \\
\hline 9 & Manufacture of furniture & NEI \\
\hline 10 & $\begin{array}{l}\text { Manufacture of pulp, paper, and paper } \\
\text { products }\end{array}$ & EI \\
\hline 11 & $\begin{array}{l}\text { Publishing, printing, and reproduction } \\
\text { of recorded media }\end{array}$ & NEI \\
\hline 12 & $\begin{array}{c}\text { Manufacture of stationery and } \\
\text { sporting goods }\end{array}$ & NEI \\
\hline 13 & $\begin{array}{l}\text { Manufacture of petroleum processing, } \\
\text { coking, and nuclear fuel }\end{array}$ & EI \\
\hline 14 & $\begin{array}{l}\text { Manufacture of chemicals, chemical } \\
\text { products }\end{array}$ & EI \\
\hline 15 & Manufacture of pharmaceutical & NEI \\
\hline 16 & Manufacture of chemicals fibers & NEI \\
\hline 17 & Manufacture of rubber & NEI \\
\hline 18 & Manufacture of plastic products & NEI \\
\hline 19 & $\begin{array}{l}\text { Manufacture of other nonmetallic } \\
\text { mineral products }\end{array}$ & EI \\
\hline 20 & $\begin{array}{l}\text { Manufacture of ferrous metal smelting } \\
\text { and rolling }\end{array}$ & EI \\
\hline 21 & $\begin{array}{c}\text { Manufacture of nonferrous metal } \\
\text { smelting and rolling }\end{array}$ & NEI \\
\hline 22 & Manufacture of mineral product & NEI \\
\hline 23 & Manufacture of general equipment & NEI \\
\hline 24 & Manufacture of special equipment & NEI \\
\hline 25 & Manufacture of transport equipment & NEI \\
\hline 26 & Manufacture of electrical machinery & NEI \\
\hline 27 & $\begin{array}{c}\text { Manufacture of communication } \\
\text { equipment computer and other } \\
\text { electronic equipment }\end{array}$ & NEI \\
\hline 28 & $\begin{array}{l}\text { Manufacture of instrument and office } \\
\text { machinery }\end{array}$ & NEI \\
\hline
\end{tabular}

3.3. Data Source and Processing. The energy data used in this paper are derived from Energy Balance Sheet of China Energy Statistical Yearbook (1996-2013). Other data come from the Statistical Yearbook of China (1996-2013). To eliminate the effect of price changes, we converted the GDP at current price to the GDP at constant price in 1995 with index reduction method, and the price indexes come from China Statistical Yearbook.
3.4. Decomposition Carbon Emissions Based on LMDI Model. According to LMDI model, the total change in carbon emissions over the period ( 0 to $T)\left(\Delta C_{T}\right)$ is the sum of the changes, including the changes in production scale $\left(\Delta C_{p}\right)$, the changes in intrastructure $\left(\Delta C_{s}\right)$, the changes in energy intensity $\left(\Delta C_{i}\right)$, the changes in fuel mix $\left(\Delta C_{m}\right)$, and the changes in carbon emissions coefficient $\left(\Delta C_{e}\right)$. Carbon emissions coefficients of different basic fuels are approximately constant in China in the actual application; therefore $\Delta C_{e}=0$.

The total change in carbon emissions can be expressed as

$$
\Delta C_{T}=\Delta C_{p}+\Delta C_{s}+\Delta C_{i}+\Delta C_{m}
$$

For $i$ manufacturing subsector consuming $j$ fuels, the total carbon emissions are given by

$$
C=\sum_{i j} C_{i j}=\sum_{i j} P \frac{P_{i}}{P} \frac{E_{i}}{P_{i}} \frac{E_{i j}}{E_{i}} \frac{C_{i j}}{E_{i j}}=\sum_{i j} P S_{i} I_{i} M_{i j} U_{i j}
$$

where $P$ is the output of manufacturing sector, $P_{i}$ is the output of subsector $i, E_{i}$ is the energy consumption of subsector $i, E_{i j}$ is the consumption of fuel $j$ in subsector $i, C_{i j}$ is the carbon emissions of fuel $j$ in subsector $i, S_{i}=\left(P_{i} / P\right)$ is the output share occupied by subsector $i$, and $I_{i}=\left(E_{i} / P_{i}\right)$ is the energy intensity of subsector $i$. And $M_{i j}=\left(E_{i j} / E_{i}\right)$ represents the proportion of energy in subsector $i$ supplied by fuel $j$ and $U_{i j}=\left(C_{i j} / E_{i j}\right)$ is carbon emissions coefficient factor of fuel $j$ in subsector $i$.

The components of change in (1) are the following:

$$
\begin{aligned}
\Delta C_{p} & =\sum_{i j} L\left(C_{i j}^{t-1}, C_{i j}^{t}\right) \ln \left[\frac{P(t)}{P(t-1)}\right] \\
\Delta C_{s} & =\sum_{i j} L\left(C_{i j}^{t-1}, C_{i j}^{t}\right) \ln \left[\frac{S_{i}(t)}{S_{i}(t-1)}\right] \\
\Delta C_{i} & =\sum_{i j} L\left(C_{i j}^{t-1}, C_{i j}^{t}\right) \ln \left[\frac{I_{i j}(t)}{I_{i j}(t-1)}\right] \\
\Delta C_{m} & =\sum_{i j} L\left(C_{i j}^{t-1}, C_{i j}^{t}\right) \ln \left[\frac{M_{i j}(t)}{M_{i j}(t-1)}\right],
\end{aligned}
$$

where

$$
L\left(C_{i j}^{t-1}, C_{i j}^{t}\right)= \begin{cases}\frac{C_{i j}^{t}-C_{i j}^{t-1}}{\ln \left(C_{i j}^{t} / C_{i j}^{t-1}\right)} & \left(C_{i j}^{t-1} \neq C_{i j}^{t}\right) \\ C_{i j}^{t-1} \text { or } C_{i j}^{t} & \left(C_{i j}^{t-1}=C_{i j}^{t}\right) .\end{cases}
$$

Equation (3) denotes the production effect, intrastructure effect, energy intensity effect, and fuel mix effect, respectively. 
TABLE 2: Eight decoupling states divided by Tapio [15].

\begin{tabular}{|c|c|c|c|}
\hline Decoupling states & $\Delta C / C$ & $\Delta \mathrm{GDP} / \mathrm{GDP}$ & Decoupling elasticity values $(D)$ \\
\hline \multicolumn{4}{|l|}{ Negative decoupling } \\
\hline Expansive negative decoupling & $>0$ & $>0$ & $D>1.2$ \\
\hline Strong negative decoupling & $>0$ & $<0$ & $D<0$ \\
\hline Weak negative decoupling & $<0$ & $<0$ & $0<D<0.8$ \\
\hline \multicolumn{4}{|l|}{ Decoupling } \\
\hline Weak decoupling & $>0$ & $>0$ & $0<D<0.8$ \\
\hline Strong decoupling & $<0$ & $>0$ & $D<0$ \\
\hline Recessive decoupling & $<0$ & $<0$ & $D>1.2$ \\
\hline \multicolumn{4}{|l|}{ Coupling } \\
\hline Expansive coupling & $>0$ & $>0$ & $0.8<D<1.2$ \\
\hline Recessive coupling & $<0$ & $<0$ & $0.8<D<1.2$ \\
\hline
\end{tabular}

To measure the effect contribution of each factor, we define them as follows:

$$
\begin{gathered}
g_{p}=\frac{\Delta C_{p}}{\Delta C}, \\
g_{s}=\frac{\Delta C_{s}}{\Delta C}, \\
g_{i}=\frac{\Delta C_{i}}{\Delta C}, \\
g_{m}=\frac{\Delta C_{m}}{\Delta C},
\end{gathered}
$$

where $g_{p}, g_{s}, g_{i}$, and $g_{m}$ indicate the effect contribution values of production scale, intrastructure, energy intensity, and fuel mix, respectively.

3.5. Decoupling Model between Carbon Emissions and Economic Growth. In order to study the decoupling relation between energy relationship between carbon emissions and economic growth further, the decoupling model could be decomposed into five elasticity values, and the model is given as follows:

$$
\begin{aligned}
D_{i}= & \frac{\Delta C_{i} / C_{i}}{\Delta \mathrm{GDP} / \mathrm{GDP}} \\
= & \frac{\Delta C_{i} / C_{i}}{\Delta E_{i} / E_{i}} \cdot \frac{\Delta E_{i} / E_{i}}{\Delta P_{i} / P_{i}} \cdot \frac{\Delta P_{i} / P_{i}}{\Delta \mathrm{IGDP} / \mathrm{IGDP}} \\
& \cdot \frac{\mathrm{IGDP} / \mathrm{IGDP}}{\Delta \mathrm{GDP} / \mathrm{GDP}},
\end{aligned}
$$

where $D_{i}$ denotes the decoupling elasticity between carbon emissions from subsector $i$ and economic growth, $C$ is the carbon emissions from subsector $i$ at base year, GDP and IGDP are the gross domestic product and the secondary industry product value at base year, and $E_{i}$ and $P_{i}$ denote energy consumption and output value of subsector $i$, respectively. $\Delta C_{i}, E_{i}$, and $\Delta P_{i}$ denote increment of carbon emissions, energy consumption, output value of subsector $i$, respectively, and $\triangle$ IGDP and $\triangle$ GDP denote the increment of secondary industry product value and the gross domestic product.
$\left(\Delta C_{i} / C_{i}\right) /\left(\Delta E_{i} / E_{i}\right)$ is the carbon reduction decoupling elasticity, reflecting the elasticity between carbon emissions of subsector $i$ and energy consumption, $\left(\Delta E_{i} / E_{i}\right) /\left(\Delta P_{i} / P_{i}\right)$ is the energy conservation decoupling elasticity, describing the elasticity between energy consumption of subsector $i$ and manufacturing output value, $\left(\Delta P_{i} / P_{i}\right) /(\Delta \mathrm{IGDP} / \mathrm{IGDP})$ is the output value decoupling elasticity, describing the elasticity between product value of subsector $i$ and that of the secondary industry, and $(\triangle \mathrm{IGDP} / \mathrm{IGDP}) /(\Delta \mathrm{GDP} / \mathrm{GDP})$ is the industrial development decoupling elasticity, describing the elasticity between the secondary industry product value and the GDP. Additionally, the decoupling states defined by Tapio are presented in Table 2 according to the decoupling elasticity value.

\section{Results and Discussion}

4.1. Changes of Energy-Related Carbon Emissions. As is shown in Figure 1 and Table 3, the energy-related carbon emissions of China manufacturing increased rapidly from $36988.97 \times 10^{4}$ tons of carbon in 1996 to $74923.45 \times 10^{4}$ tons of carbon in 2012 by $6.41 \%$ per annum and present obvious change during the different period. The average carbon emissions of EI subsector from 1996 to 2012 account for $83 \%$ of the total amount of carbon emissions from manufacturing sector, but its output value only takes up $28 \%$ of total manufacturing sector. The carbon emissions of NEI subsector change little during the period, while both the carbon emissions from EI subsector and the total manufacturing sector fluctuate from 1996 to 2012.

(1) Low carbon emissions and falling trend period (19962001): the energy consumption from manufacturing sector and EI subsector in this period decreased gradually, showing falling trend with the year changing. Mainly because of the financial crisis from Asia in 1997, China economy, especially the manufacturing, was affected, and the slow growth rate of manufacturing led to the stable low level of carbon emissions in the whole country.

(2) Rapid growth period (2002-2012): the feature of carbon emissions from manufacturing sector and EI subsector in this period was much higher increasing speed and much bigger amount of carbon emissions. Except the fall in 2010, 
TABLE 3: The proportion of output value and carbon emissions of EI subsector, NEI subsector to the total amount of manufacturing sector in 1996-2012.

\begin{tabular}{lcccc}
\hline \multirow{2}{*}{ Year } & \multicolumn{2}{c}{ Output value proportion } & \multicolumn{2}{c}{ Carbon emissions proportion } \\
& EI & NEI & EI & NEI \\
\hline 1996 & $28 \%$ & $72 \%$ & $78 \%$ & $22 \%$ \\
1997 & $28 \%$ & $72 \%$ & $79 \%$ & $21 \%$ \\
1998 & $26 \%$ & $74 \%$ & $79 \%$ & $21 \%$ \\
1999 & $26 \%$ & $74 \%$ & $78 \%$ & $22 \%$ \\
2000 & $27 \%$ & $73 \%$ & $80 \%$ & $20 \%$ \\
2001 & $27 \%$ & $73 \%$ & $80 \%$ & $20 \%$ \\
2002 & $26 \%$ & $74 \%$ & $80 \%$ & $20 \%$ \\
2003 & $27 \%$ & $73 \%$ & $82 \%$ & $18 \%$ \\
2004 & $29 \%$ & $71 \%$ & $84 \%$ & $16 \%$ \\
2005 & $29 \%$ & $71 \%$ & $85 \%$ & $15 \%$ \\
2006 & $29 \%$ & $71 \%$ & $86 \%$ & $14 \%$ \\
2007 & $29 \%$ & $71 \%$ & $86 \%$ & $14 \%$ \\
2008 & $30 \%$ & $70 \%$ & $86 \%$ & $14 \%$ \\
2009 & $28 \%$ & $72 \%$ & $87 \%$ & $13 \%$ \\
2010 & $29 \%$ & $71 \%$ & $87 \%$ & $13 \%$ \\
2011 & $30 \%$ & $70 \%$ & $88 \%$ & $12 \%$ \\
2012 & $29 \%$ & $71 \%$ & $89 \%$ & $11 \%$ \\
Average & $28 \%$ & $72 \%$ & $83 \%$ & $17 \%$ \\
\hline
\end{tabular}

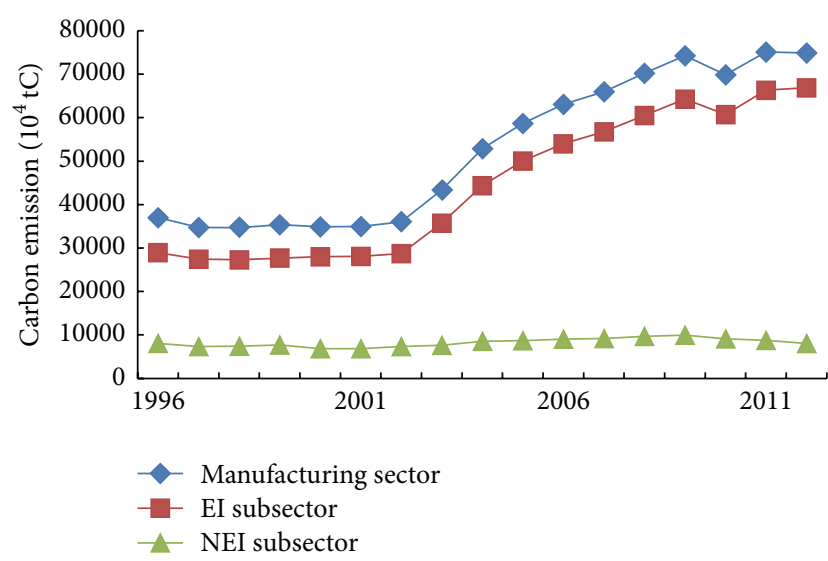

Figure 1: Change trend of carbon emissions from China's manufacturing sector and subsector in 1996-2012.

the total emission amount showed significant upward trend. Because manufacturing sector developed rapidly, the dependence on high energy consumption brought about the rapid growth of carbon emissions, after China joined WTO in 2001. Although China has been advocating transforming economic growth pattern, adjusting and optimizing the intrastructure since 2006, the carbon emissions amount has not changed correspondingly. The policy of energy conservation and reduction still faces great pressure in future to achieve the government targets in 2020 .

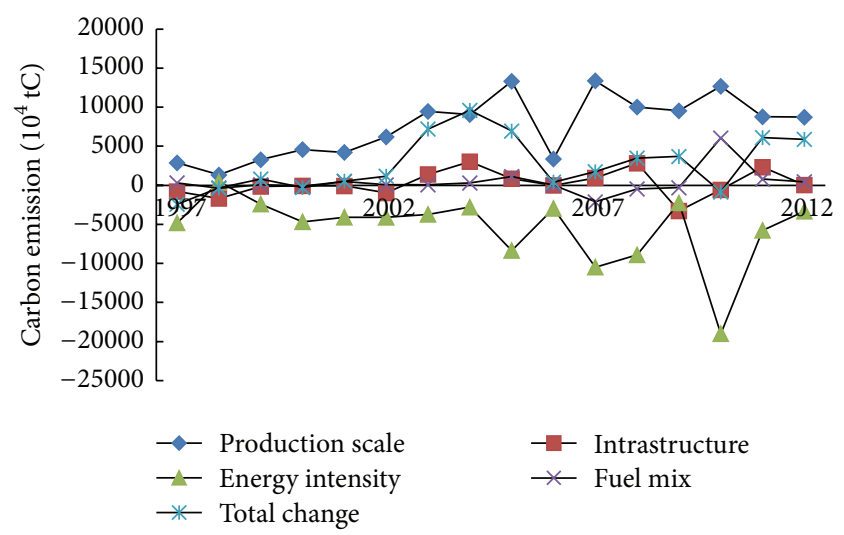

Figure 2: Annual effect of each factor on carbon emissions in the China manufacturing sector, 1997-2012.

TABLe 4: Cumulative effect contribution value of each factor on carbon emissions in the China manufacturing sector, EI, and NEI in 2012 .

\begin{tabular}{lccc}
\hline Factor & Manufacturing sector & EI & NEI \\
\hline Production scale & 2.672 & 2.46 & 3.205 \\
Intrastructure & 0.087 & 0.005 & -0.194 \\
Energy intensity & -1.994 & -1.608 & -2.158 \\
Fuel mix & 0.145 & 0.142 & 0.147 \\
\hline
\end{tabular}

4.2. Decomposition Analysis of Carbon Emissions. The annual effect of the production scale, intrastructure, energy intensity, and fuel mix on carbon emissions from manufacturing sector is shown in Figure 2. Taking 1996 as the base year, the energy intensity effect was always negative and the production scale effect was positive; both intrastructure and fuel mix had slight changes over the study period. In terms of cumulative effect contribution value of each factor in 2012, as shown in Table 4, the value of production scale was $276.2 \%$ and made the largest contribution to the changes of carbon emissions among all factors, indicating the production scale had positive effect on the increase of carbon emissions, energy intensity was an important inhibition factor of increasing carbon emissions, and its cumulative effect contribution value reached $-199.3 \%$. The results showed that although energy intensity decreases, the expansion of production from manufacturing sector could result in the increase of carbon emissions.

While the value of intrastructure and fuel mix was $8.6 \%$ and $14.4 \%$, respectively, both the change of intrastructure and fuel mix had no significant impact on curbing carbon emissions of manufacturing sector. Manufacturing sector consumed the coal for approximately over $50 \%$ of the total energy consumption during the period, and the coal was still the main fuel source of the energy consumption. Besides, within manufacturing sector, the share of each subsector did not change significantly; the output proportion of EI is still too high with few changes. Thus, both fuel structure and intrastructure of manufacturing sector need to be further optimized in order to curb the increase of carbon emissions in future. 


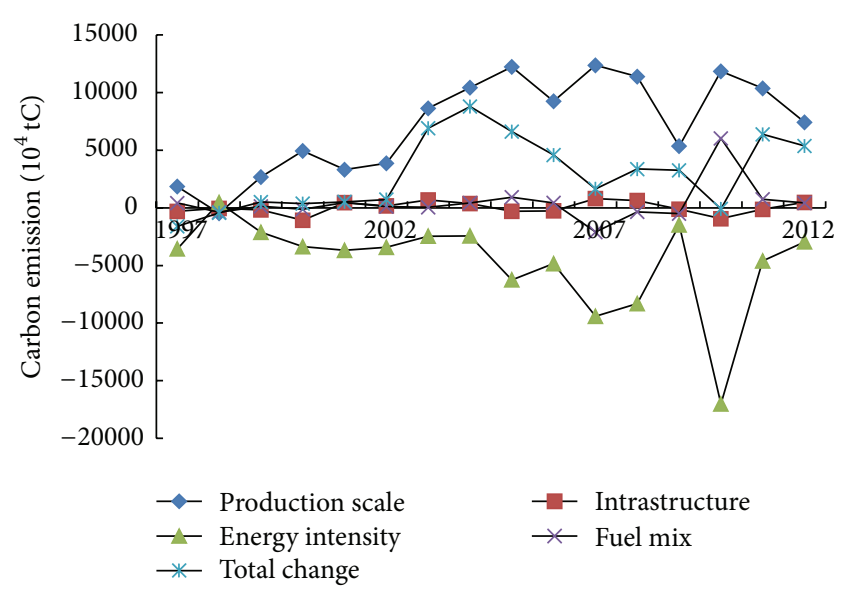

Figure 3: Annual effect of each factor on carbon emissions in EI subsector, 1997-2012.

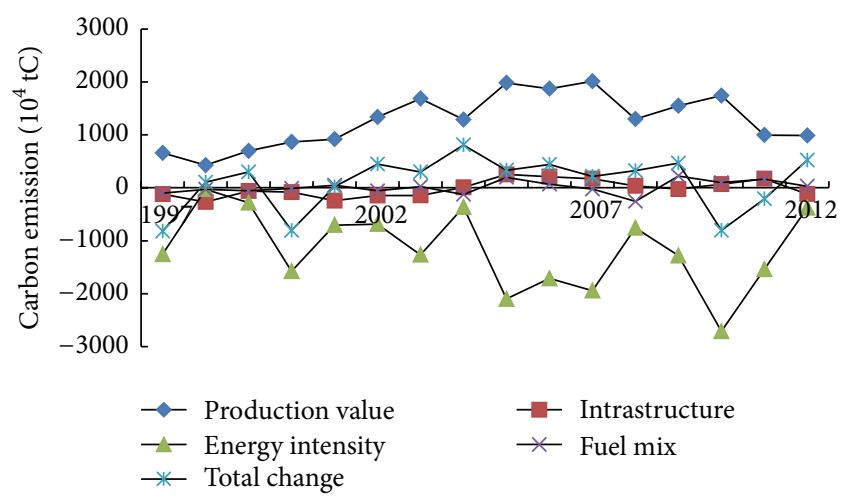

FIgUre 4: Annual effect of each factor on carbon emissions in NEI subsectors, 1997-2012.

Figures 3 and 4 represent the annual effect of each factor on the changes of carbon emissions from EI and NEI subsectors, respectively. The results showed that the effect value of EI subsector was higher than that of NEI subsector. For each subsector, both production scale and energy intensity had relatively great impact on the changes of carbon emissions during the study period. The effect of production scale on the changes of carbon emissions was positive in most of years during the study period, while energy intensity effect was negative. In comparison, both intrastructure and fuel mix had relative smaller impacts; their cumulative effect contribution values were small, showing relatively weak pushing effects on carbon emissions.

For EI subsector, in terms of cumulative effect contribution values in 2012, production scale made the largest positive contribution to the changes of carbon emissions and the value reached $246 \%$, energy intensity is the second factor, and its contribution value reached $-160.8 \%$, while the value of intrastructure and fuel mix was $0.5 \%$ and $14.2 \%$, respectively. As to NEI subsector, all the absolute cumulative effects of contribution value of factors except fuel mix were relatively higher than EI subsector, whose contribution value of the

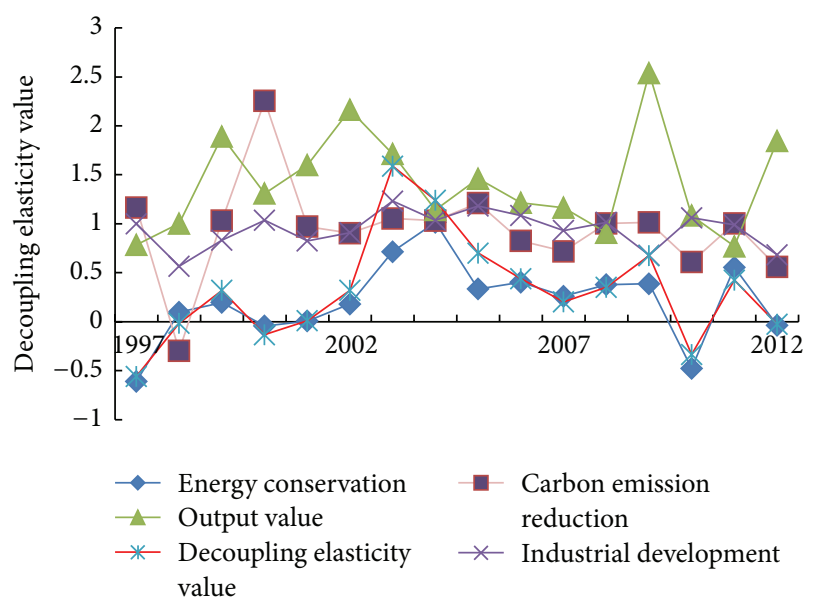

FIGURE 5: Change trends of decoupling elasticity values between energy-related carbon emissions and economic growth from manufacturing sector, 1997-2012.

production scale, intrastructure, energy intensity, and fuel mix was $320.5 \%,-19.4 \%,-215.8 \%$, and $14.7 \%$, respectively.

4.3. Analysis of Decoupling Elasticity. In order to analyze the relationship between carbon emissions of manufacturing sector and economic growth, the paper calculated the decoupling elasticity value according to (6). And five decoupling elasticity values of manufacturing sector and two subsectors from 1996 to 2012 could be obtained. As to the manufacturing sector, the total decoupling elasticity value was 0.163 , expressing the weak decoupling state. Comparing the four decoupling elasticity values, the output value had the biggest value, which was 1.819 presenting the expansive negative decoupling state between the output value of manufacturing sector and that of the secondary industry, while the energy conservation had the smallest value, which was 0.091 expressing the weak decoupling state between the energy consumption and the output value of manufacturing sector. For two subsectors, the weak decoupling state occurred in EI subsector, its total decoupling elasticity value was 0.208 , and the strong decoupling state appeared in NEI subsector, and its total decoupling elasticity value was -0.0003 .

The annual changes of all decoupling elasticity values from manufacturing sector, EI subsector, and NEI subsector were shown in Figures 5, 6, and 7, respectively. From the change trends of all the decoupling elasticity values during the study period, the total decoupling elasticity of carbon emissions from economic growth had the same trend as the energy conservation decoupling elasticity, it increased between 1997 and 2003 but showed a clear decline after 2003, and the decoupling state transformed from the weak decoupling state to strong decoupling state in 2012.

Decoupling elasticity of energy conservation describes the elasticity of manufacturing output value from energy consumption. For manufacturing sector, it had the same trend as the total decoupling elasticity and presented the weak or the strong decoupling state during the study period, indicating the effective policy of energy conservation in 


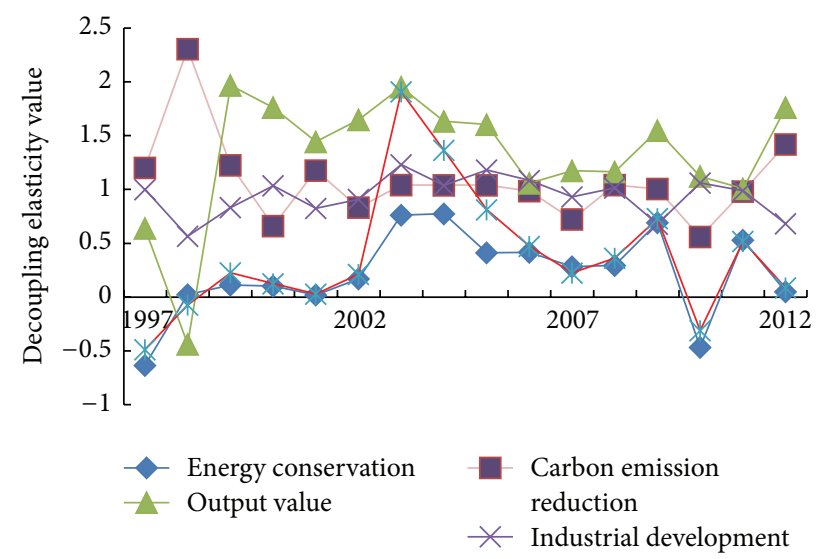

FIGURE 6: Change trends of each of the decoupling elasticity values between energy-related carbon emissions and economic growth from EI subsectors in 1997-2012.

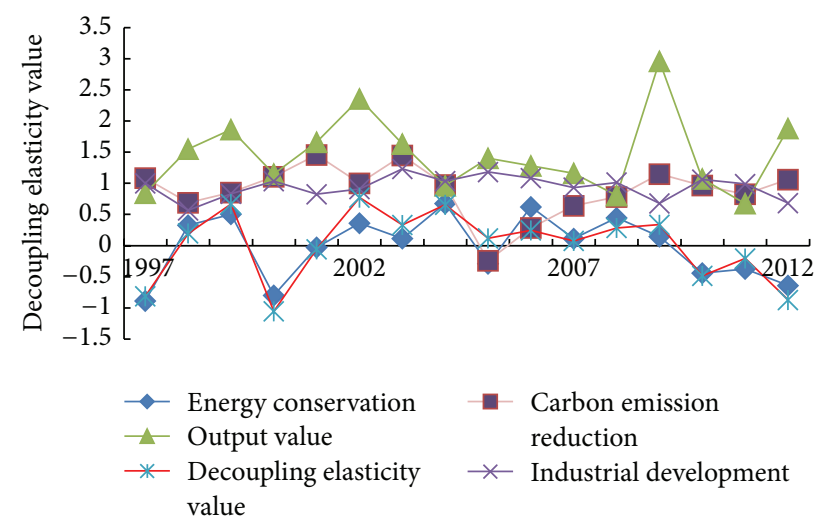

FIGURE 7: Change trends of each of the decoupling elasticity values between energy-related carbon emissions and economic growth from NEI subsectors in 1997-2012.

China owing to falling energy consumption per unit of output. Analyzing EI and NEI subsector, respectively, both two subsectors had slight change, and the state of weak decoupling often appeared in EI subsector almost every year, but the strong decoupling often occurred in NEI subsector. Either weak decoupling or strong decoupling state occurred in manufacturing sector during the study period except in 2003 and 2004, showing significant decoupling effects.

Decoupling elasticity of carbon emission reduction reflects the energy consumption elasticity of carbon emissions. For China manufacturing, it increased between 1997 and 2000 but began to decline after 2000, and the expansive coupling state appeared many times during the study period, which indicated that the policy of carbon emissions reduction in China manufacturing had little effect. Analyzing two subsectors, respectively, the expansive coupling state mainly appeared in EI subsector, while recessive coupling state mainly occurred in NEI subsector during the study period.

Decoupling elasticity of output value describes the secondary industry value of elasticity of the manufacturing sector output value. For the manufacturing sector, it expressed the state of expansive coupling or expansive negative decoupling from 1997 to 2012, indicating the production value of manufacturing sector increased more than the secondary industry. Like the total manufacturing sector, both EI and NEI subsectors were also in the state of expansive coupling state or expansive negative decoupling during the study period, but the growth rate of EI sector was lower than that of NEI subsector.

Decoupling elasticity of industrial development describes the GDP elasticity of the secondary industry output value. Either the state of expansive coupling or expansive negative decoupling mainly appeared in 1997-2012, indicating the growth rate of the secondary industry increased more than GDP. Although our government has been encouraging the development of the third industry, the secondary industry took up higher proportion of GDP, and it was $45.3 \%$ in 2012.

\section{Conclusions and Implications}

Energy-related carbon emissions from 1996 to 2012 were calculated from 28 subsectors of China manufacturing consuming 16 types of fuels, and the results indicated that carbon emissions from China manufacturing sector have been increasing rapidly since 2002 . The paper makes the analysis of the reasons of the increase of carbon emissions, and the relationship between carbon emissions and economic growth. The conclusions are as follows:

(i) Production scale was the major positive contribution factor affecting energy-related carbon emissions, which had closely relationships with the expansion of manufacturing output in recent years. However, curbing the product of manufacturing is not the feasible approach to decrease the carbon emissions for the economic growth. The way to solve the issue in the long run is to develop low carbon economy and decrease energy intensity to improve energy efficiency to coordinate the carbon emissions and economic development.

(ii) Energy intensity always had strong inhibiting effects on the increase of carbon emissions, showing downward trend during the study periods. This is connected with the energy conservation and emission reduction advocated in recent years, and particularly since the 11th Five-Year Plan period, China has been developing environment-friendly industries and the new low carbon industries, strengthening the assessment of energy conservation and the elimination of backward production capacity. So we should continue strengthening the policies of energy conservation and emission reduction, and technological innovations, in order to promote the industry upgrading and improve the energy use efficiency.

(iii) Intrastructure had weak positive influences on carbon emissions, which showed irrational structure existing within manufacturing sector, too many extensive subsectors with high energy consumption but low output. The policies of industrial structure adjustment 
advocated in China in recent years have little effects on reducing carbon emissions. So keeping optimizing intrastructure and converting extensive subsectors into intensive ones should be taken as main strategies to drive intrastructure adjustments.

(iv) Compared with the other factors, the effect of fuel mix on carbon emissions was relatively weak, which was related with the long-term dependence on coal and petrol consumption. So the government should promote energy structure adjustment and develop reproducible energy such as nuclear energy, water energy, wind energy, solar energy, and bioenergy, to optimize fuel structure and decrease the dependence of energy consumption on fossil energy in future.

(v) Only 5 subsectors in the 28 subsectors of manufacturing were classified as EI subsector, which accounted for $28 \%$ of total manufacturing output value but contributed $83 \%$ to the total carbon emissions of manufacturing sector. Both EI and NEI subsectors had two same factors of affecting emission change, production scale, and energy intensity, while the effect values of the two factors in EI subsector were much higher than that in NEI subsector, but the cumulative effect contribution values were relatively lower. Therefore, the EI subsector still has much more potentiality of energy conservation and emission reduction than NEI subsector.

(vi) Weak decoupling of manufacturing sector carbon emissions from GDP could be observed during the study period. Weak decoupling state in EI subsector and strong decoupling state in NEI subsector were observed in most years of the study period. In order to sustain the decoupling relationship between carbon emissions of manufacturing sector and GDP, our government need to strengthen the decoupling elasticity of energy conservation and carbon emissions reduction.

There are some limitations in the paper. Carbon emissions are only involved in the final energy consumptions without considering the production process which also generates carbon emissions. In addition, carbon emissions from manufacturing sector at the provincial level should be studied so as to establish appropriate and specific low carbon policies and measures for the large difference of province, which is the direction of the research in future.

\section{Conflict of Interests}

The authors declare that there is no conflict of interests regarding the publication of this paper.

\section{Acknowledgments}

The authors gratefully acknowledge the Natural Science Foundation of China for Grant Support (no. 41401163) and Shandong Province Soft Science for Grant Support (no. 2014RZB01009, no. 2013RZB01023).

\section{References}

[1] W.-X. Wang, Y.-Q. Kuang, N. Huang, and D. Zhao, "Empirical research on decoupling relationship between energy-related carbon emission and economic growth in Guangdong province based on extended kaya identity," The Scientific World Journal, vol. 2014, Article ID 782750, 11 pages, 2014.

[2] Z.-W. Gong and J. Wu, "The energy consumption and it's intensity forecast of China's manufacturing industry," in Proceedings of the 4th Symposium of Chinese Scientifically and Technological Policies and the Annual Conference of 4th Science and Technology Policy Studies of China (II), October 2008.

[3] B. W. Ang, "Decomposition analysis for policymaking in energy: which is the preferred method?" Energy Policy, vol. 32, no. 9, pp. 1131-1139, 2004.

[4] L. F. Wang, W. J. Duan, M. Y. Lai et al., "Study on the regional differences and industry differences of energy-saving potentiality in China's manufacturing industry," Geographical Research, vol. 34, no. 1, pp. 101-121, 2015.

[5] C. Liu, "An overview for decomposition of industry energy consumption," American Journal of Applied Science, vol. 2, no. 7, pp. 1166-11687, 2005.

[6] J. Dong and X. Zhang, "Decomposition of carbon emissions and low carbon strategies for industrial sector energy consumption in China," Resources Science, vol. 32, no. 10, pp. 1856-1862, 2010.

[7] C. Wei and D. Xia, "A decomposition analysis of per capita $\mathrm{CO}_{2}$ emission of China: based on cross-country comparison," Management Review, vol. 22, no. 8, pp. 1856-1862, 2010.

[8] J.-K. Song, "Factor decomposition of carbon emissions from energy consumption of Shandong Province based on LMDI," Resources Science, vol. 34, no. 3, pp. 35-41, 2012.

[9] G. P. Hammond and J. B. Norman, "Decomposition analysis of energy-related carbon emissions from UK manufacturing," Energy, vol. 41, no. 1, pp. 220-227, 2012.

[10] M. E. H. Arouri, A. Ben Youssef, H. M'henni, and C. Rault, "Energy consumption, economic growth and $\mathrm{CO}_{2}$ emissions in Middle East and North African countries," Energy Policy, vol. 45, pp. 342-349, 2012.

[11] B. Saboori and J. Sulaiman, "Environmental degradation, economic growth and energy consumption: evidence of the environmental Kuznets curve in Malaysia," Energy Policy, vol. 60, pp. 892-905, 2013.

[12] S. Niu, Y. Ding, Y. Niu, Y. Li, and G. Luo, "Economic growth, energy conservation and emissions reduction: a comparative analysis based on panel data for 8 Asian-Pacific countries," Energy Policy, vol. 39, no. 4, pp. 2121-2131, 2011.

[13] K. Alkhathlan and M. Javid, "Energy consumption, carbon emissions and economic growth in saudi arabia: an aggregate and disaggregate analysis," Energy Policy, vol. 62, pp. 1525-1532, 2013.

[14] OECD, "Indicators to measure decoupling of environmental pressures from economic growth," Tech. Rep., OECD, Paris, France, 2002.

[15] P. Tapio, "Towards a theory of decoupling: degrees of decoupling in the EU and the case of road traffic in Finland between 1970 and 2001," Transport Policy, vol. 12, no. 2, pp. 137-151, 2005.

[16] M. F. Zhuang, Decoupling index and evaluation of industrial and transportation departments in Taiwan [Ph.D. thesis], National Taipei University, Taipei, Taiwan, 2006.

[17] X.-S. Li, F.-T. Qu, and Z.-X. Guo, "Decoupling between urban and rural construction land," China Population, Resources and Environment, vol. 18, no. 5, pp. 179-184, 2008. 
[18] X. Pan, F.-S. Tao, and D.-W. Xu, "On the changes in the carbon emissions intensity of China's manufacturing industry and its factors decomposition," China Population, Resources and Environment, vol. 21, no. 5, pp. 101-105, 2011.

[19] Intergovernmental Panel on Climate Change (IPCC), "IPCC guidelines for national greenhouse gas inventories," 2006, http://www.ipcc-nggip.iges.or.jp. 


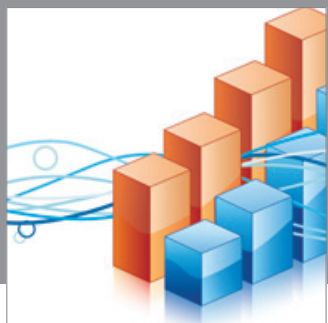

Advances in

Operations Research

mansans

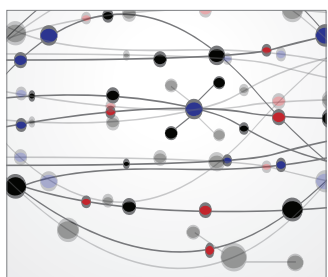

The Scientific World Journal
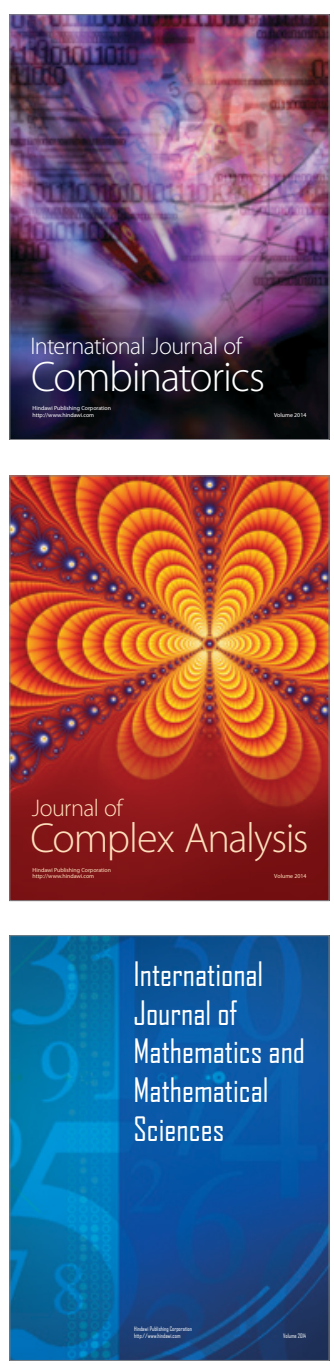
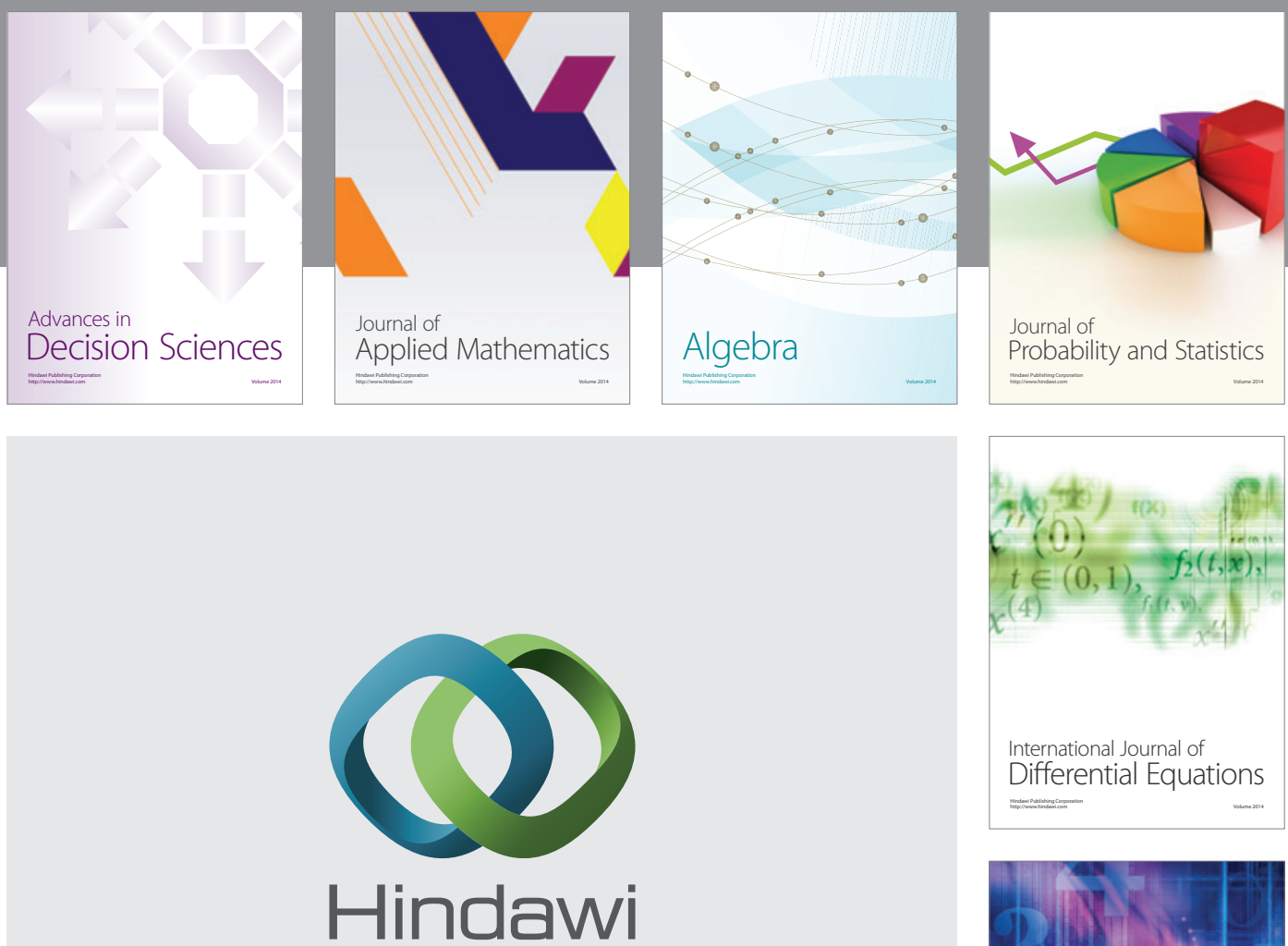

Submit your manuscripts at http://www.hindawi.com
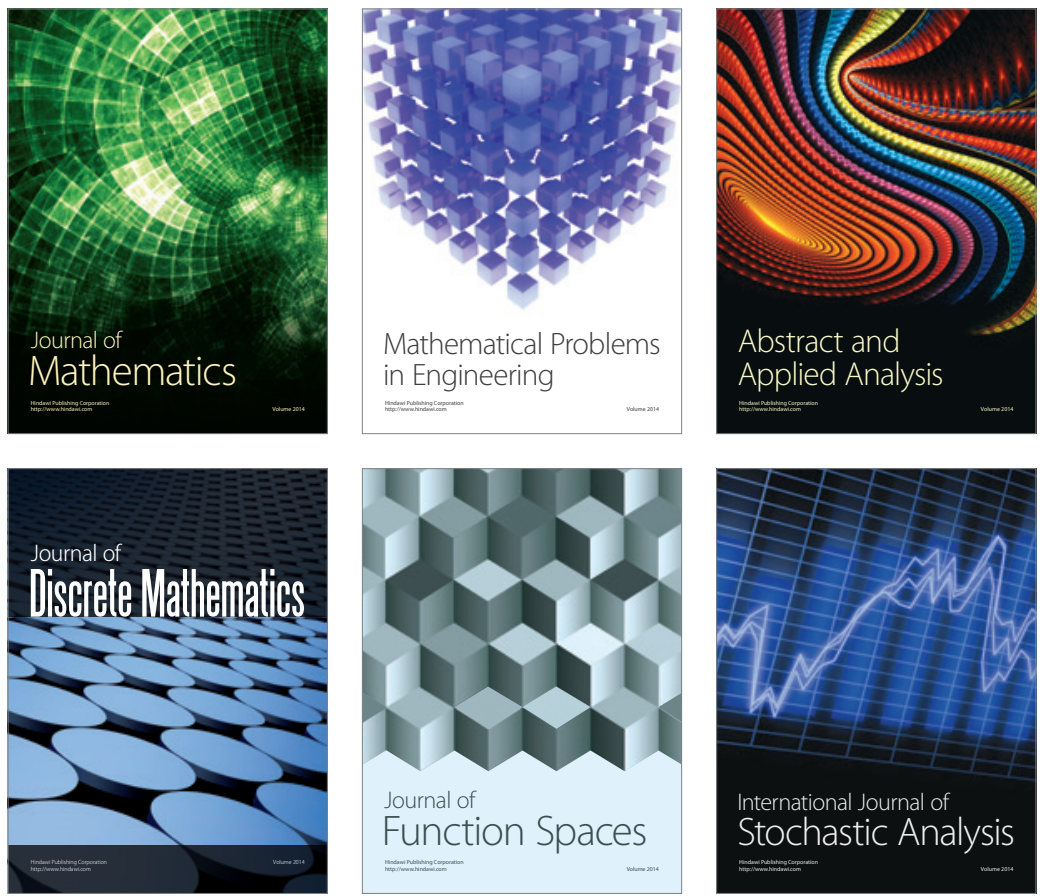

Journal of

Function Spaces

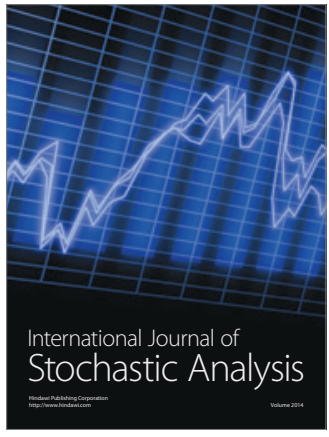

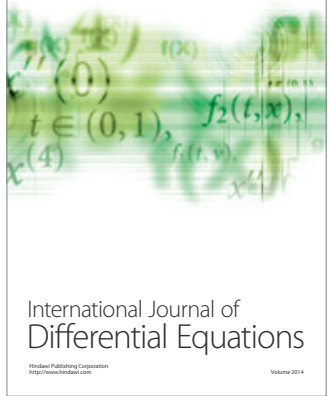
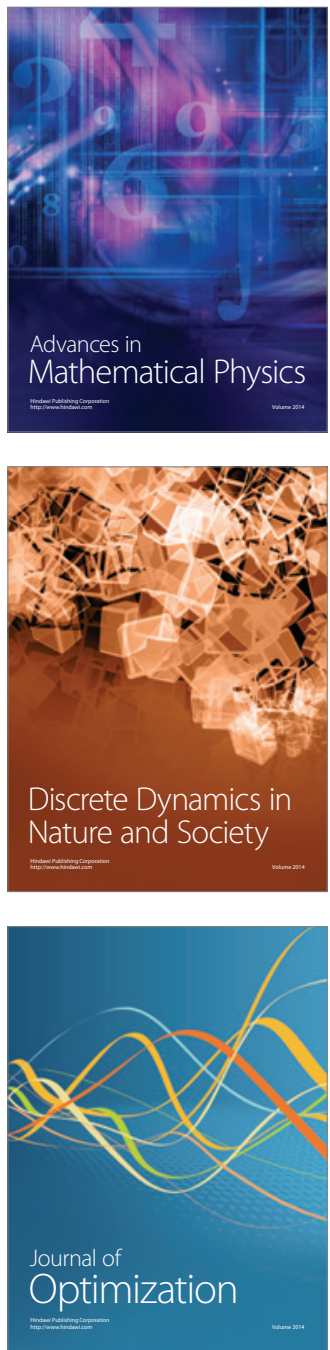